\title{
UROBORIC INCEST IN WHITMAN'S "THE SLEEPERS"
}

\author{
Michael RAINER
}

Most OF THE CRITICISM of Walt Whitman's "The Sleepers," perhaps the most startling and modern of the untitled poems in the 1855 edition of Leaves of Grass, has focused on discovering a unity, a schematic, that will allow the reader to understand the seemingly chaotic images in the poem. The dream images, so faithful to the dream state, have naturally sent critics to studies of dream analysis. ${ }^{1}$ Some critics have turned to Jung for help in explicating the poem, particularly since Jung's theories encompass the archetype and the collective unconscious, which lend themselves to an understanding of Whitman's impetus to define and transcend the distance between the "I" and the "You" in the 1855 edition of Leaves. But most critics have ignored the discoveries of Jung's disciples, who have plumbed the depths that Jung only charted and that Whitman, as artist, fathomed intuitively. ${ }^{2}$ One particularly useful concept, developed by Erich Neumann in The Origins and History of Consciousness and endorsed by Jung, is that of uroboric incest, the return of the conscious to a pre-conscious state, a regression that is of major import to the dream state and to Whitman's poem. ${ }^{3}$ An understanding of the state of uroboric incest will demonstrate the unity of "The Sleepers," its faithfulness to an identifiable psychological state, and its use of particularly telling images.

A short explication of uroboric incest, as defined by Neumann, is necessary. ${ }^{4}$ Neumann equates the growth of the individual consciousness, as it drags itself from the murkiness of the unconscious, with the growth of consciousness in mankind; thus the emphasis on myth, primitive art, and literature as a means of exploring the development of man's consciousness and his archetypal patterns. Neumann's symbol for the preconscious state is the uroboros (the snake with its tail in its mouth), a symbol of perfect unity: "Circle, sphere, and round are all aspects of the self-contained, which is without beginning and end; in its preworldly perfection it is prior to any process. . . . It is also the perfect state in which opposites are united." ${ }^{5}$ Consciousness is, therefore, a process of defining the self, moving from the preconscious state of the uroboros to the state of the self, the state of the ego. The tug of the preconscious remains with the individual throughout life, and there is a tension between the desire to be conscious, and therefore separate, and the desire to return to the preconscious, the realm of the whole. The uroboros is a symbol of "the time of existence in paradise where the psyche has her preworldly abode, the time before the birth of the ego, the 
time of unconscious envelopment, of swimming in the ocean of the unborn." The ego's desire to drown, or at least to swim, in the uroboric state of preconsciousness is uroboric incest. This state is not an aberration; indeed, "regression to, and fixation at, this level occupy an important place in the life of the average person, ... and a decidedly positive one in the life of the creative man." 7 For the fully conscious man, uroboric incest most often takes the form of sleep: "Consciousness re-experiences its emergence from the unconscious in the growth of childhood, and every night in sleep, dying with the sun, it sinks back into the depths of the unconscious, to be reborn in the morning and to begin the day anew." It is in this sense that "The Sleepers" is an example of uroboric incest, and a tracing of the development of the poem in light of this concept will demonstrate its unity and universality.

Entering the uroboros describes the initial progress of the sleeper-persona in the poem. As the poem begins, the sleeper is confused: "lost to myself, ill assorted, contradictory." 9 The sleeper is aware of his individuality, the distance and space that exist between himself and the other selves, the "corpses," the "onanists," and even the "married couple." He is aware of his separation ("I pass my hands soothingly to and fro a few inches from them") and his connection to the others ("all, all sleep"). After this initial tension, the sleeper merges with the others: "Now I pierce the darkness," and "The earth recedes." As the night recedes and the poet merges with the other sleepers, contradictions begin to dissolve: "I saw that it was beautiful, and I see that what is not the earth is beautiful." The poet, in these lines, indicates his loss of individuality (at least in part, for he never completely loses himself), his entrance into the racial unconscious and, therefore, the state of uroboric incest. His use of the imagery of the night, while in keeping with the theme of the poem (sleep), is more importantly in keeping with the images that converge in the uroboros: night, darkness, the sea, the womb, the mother. And entrance into the uroboros erases contradiction.

What follows is a sense of the sleeper moving into the other sleepers, somehow coming closer and closer until merging. First, "I sleep close with the other sleepers each in turn" (1. 29). Then the sleeper dreams the others' dreams; finally, "I become the other dreamers" (1. 31). The giving up of the individual consciousness is a moment of ecstasy, exemplified by the dance. Suddenly, things that were hidden are no longer: "Only from me can they hide nothing" (1. 37); and contradictions are reconciled without logic: "I reckon I am their boss and they make me a pet besides" (1. 38). This reconciliation of opposites is certainly fitting for a state of mind whose symbol is the circle. The sleeper picks up and discards identities: "the actor, the actress, the voter, the politician." Then the masculine speaker becomes "she who adorn'd herself and folded her hair expectantly" (1. 46). As the sleeper becomes a woman and takes a lover, he maintains some aspects of the masculine ("I roll myself upon you as upon a bed"). The problems of whether the 
sleeper is masculine or feminine, of whether he is active or passive, of whether there is a lover who is not the night, dissolve when the reader understands the uroboric state and its hermaphroditic nature. ${ }^{10}$ The sleeper, who has earlier merged with the other sleepers, now completes the merging by folding (a uroboric motion) into himself, into darkness, into his lover: "I hear the heart-beat, I follow, I fade away" (1. 59). His entrance into the uroboros is complete.

It is possible at this point to suggest why Whitman excised eleven lines from the original poem. These lines ["O Hot-Cheek'd and Blushing"] tell of the speaker finding himself naked upon a pier, "ashamed to go naked about the world." What follows are elaborate sexual images: phallic ("ear of rosecorn," "white teeth," "the boss-tooth advances in darkness") and ejaculatory ("life-swelling yolks," "milky," "liquor is spilled"). ${ }^{11}$ These lines, excised from the 1881 and thus from all subsequent editions, are in opposition to the movement of the poem. The awakening of sexuality described in these lines is the opposite of the moving away from the ego that has been taking place and is not in keeping with the movement into the preconscious. By excising these lines, Whitman maintains the thrust of the poem and avoids breaking the development that continues in Section 2.

Moving deeper into the preconscious state in Section 2, the sleeper descends, and his osmosis is completed. He now is "the old woman" sitting and darning his grandson's stockings; he is "the sleepless widow"; he is "the shroud." The images pulse; they circle each other in an elaborate dance. For the state of the preconscious is not only the realm of the collective unconscious, but is also the realm of darkness and death since death is the giving up of the ego. However, in the uroboros death is not an evil. ${ }^{12}$ And although the sleeper enters the coffin and becomes a corpse, he has no fear: "it is not evil or pain here, it is blank here, for reasons" (1. 67). From this lack of pain the sleeper draws a moral: "Whoever is not in his coffin and in the dark grave let him know he has enough" (1.69). This statement, an aside placed in parentheses, is the tug of the individual consciousness, submerged in the darkness, but not extinguished. These lines $(68-69)$ lead directly into the next sections, in which the "I" pulls back slightly from the union in the uroboros and becomes an observer, less of a participant.

In Section 3, the sleeper witnesses the drowning of the "beautiful gigantic swimmer," the symbol for the collective man, what Neumann calls the Great Individual, who is "the exemplar of a process which subsequently affects all individuals in varying degree."13 The fear that the ego feels in surrendering itself is made external, and the sleeper "hates" the "swift-running eddies." The swimmer, "baffled" (1. 77) much the same as the sleeper was first "confused", (1. 4), struggles, but is borne away in the "circling eddies" and is finally taken out of sight, drowning in the water, symbol of the state of uroboric incest. The fear of the sleeper, that he might be borne away 
never to return to consciousness, is expressed in this section.

In Section 4, the sleeper turns but cannot "extricate" himself from his fears, and from the darkness arises "a past-reading." As in Section 3, this scene takes place on the shore, the sleeper standing helpless while watching others drown in the waters of the preconscious. His fear is more intensive: the beach is "cut by the razory ice-wind"; the surf is cold; and the sailors do not disappear as the gigantic swimmer did; instead, they are washed up on the shore as corpses. Once submerged in the great waters of the unconscious, they are dead to the world of the conscious.

Section 5 is in contrast to the earlier two sections (3 and 4). The "I" disappears. The sleeper as witness is completely removed from this vignette, properly so since this is a memory from the racial unconscious, a memory of the departing hero (with Washington being the closest thing to a mythical hero for America). And although the scene is filled with tears and weeping $(11.92,99)$, the moment is one of being saved. Washington crosses the water to safety. Section 6 , in contrast to Section 5, is a personal memory, a family memory, but the sleeper is no more present than before: "Now what my mother told me one day as we sat at dinner together" (1. 100). This vignette is also a happy moment, with his mother's awe at the purity of the primitive red squaw, so perfect in body, voice, and spirit. This moment is also marred by parting: "She [the mother] remember'd her many a winter and many a summer, / But the red squaw never came nor was heard of there again" (ll. 115-116). Yet she lives in the memory of the mother and ultimately in the son; she is lost, like Washington, to the touch but not to the memory of the dream. These two sections, 5 and 6, are in juxtaposition to Sections 3 and 4. In the first two, the fear of the sleeper that he will drown in the uroboric state is expressed; in the second, this fear is negated by the insight he gains into the beauty of diving into the unconscious and retrieving memories otherwise lost. The realization of this healing process is not acknowledged by the sleeper until Section 7. ${ }^{14}$

With Section 7, the sleeper again reconciles opposites: jealousy and friendliness (1. 118) and the seasons (11.120-121), as "elements merge in the night, ships make tacks in the dreams" (1. 123). The images in this section are those of safety, in contrast to the fear pervading Sections 4 and 5 . The world "home" becomes the central image, as "the exile returns home" (1. 124) and "the beautiful lost swimmer" (1. 133) and even the "red squaw" (1. 139) are safe. They have been "averaged" (1.142), that is, reduced or increased to a common state: in once sense the state of sleep; in another the state of uroboric incest. In this section the sleeper comes to terms with his fear of letting go, and the fear is replaced by a sense of peace (11. 146-147). As he comes to an understanding of the state he once feared, the themes of restoration and rebirth enter, themes characteristic of movement into and out of uroboric incest. ${ }^{15}$ Peace and night are intricately linked: "The myth of heaven indi- 
cates peace and night" (1. 148); and the image of rebirth is elaborately drawn: the soul "comes from its embower'd garden [the womb] and looks pleasantly on itself and encloses the world" (1. 151), that is, encloses the world within itself, within its developing ego. This sense of restoration and peace encompasses the outer world as well as the inner: "The Universe is duly in order, every thing is in its place" (1. 155). And although images of ill health enter the poem, they are part of a process ("in their turns"), and in the state of sleep, "they unite now" (1.160) and are made whole.

The movement in Section 8 reverses that of Section 1. The sleeper begins the section by withdrawing from the sleepers he has entered earlier (1. 26). But the sleepers he now sees are united: "They flow hand in hand over the whole earth from east to west as they lie unclothed" (1. 162). All differences have disappeared, including race, nationality, education, sex. Even the slave and master are hand in hand. Finally the sleepers awake, healed by their journey into the unconscious. The sleeper then withdraws from sleep: "I too pass from the night" (1. 177). But he pauses to pay tribute to the night, which he identifies as "my mother." Both the joyful and restful movement out of uroboric incest and the identification of the state and the night with the mother are in keeping with Neumann's explanation of this type of sleep. The process is completed. The sleeper, after moving into the uroboros, feeling fear at losing himself, finding joy and love, and coming to terms with the state of the unconscious, pays tribute to the healing power of uroboric incest: "I am not afraid, I have been well brought forward by you" (1. 180).

This explication of "The Sleepers," while not a radical departure from earlier criticism, does demonstrate the psychological unity of the poem and Whitman's brilliant understanding of the relationship between the individual and the collective consciousness. Whitman's poem is not grounded in the chaos of sleep, but in the order of great art.

The University of Georgia

\section{NOTES}

1 Robert E. Abrams, "The Function of Dreams and Dream-logic in Whitman's Poetry," Texas Studies in Literature and Language, 17 (1975), 599-616; Mutlu Blasing, “The Sleepers': The Problem of the Self in Whitman," Walt Whitman Review, 21 (1975), 11-119.

2 Shortly after I finished this article, Martin Bickman's book The Unsounded Centre: Fungian Studies in American Romanticism (Chapel Hill: University of North Carolina Press, 1980) was published. Mr. Bickman also uses Neumann as a source and examines "The Sleepers" (pp. 101116). However, he neither sees this approach as one to illuminate all the problems with the poem (p. 101), nor does he examine the excised passages. We do not agree on most major points; however, Mr. Bickman's book is a fascinating and extensive study and well worth reading. 
3 Erich Neumann, The Origins and History of Consciousness, translated by R. F. C. Hull (New York: Pantheon Books, 1954).

4 Despite the use of the word "incest," no sexual connotation is meant.

5 Neumann, p. 8.

6 Neumann, p. 12.

7 Neumann, p. 278.

8 Neumann, p. 18.

9 Leaves of Grass, Comprehensive Reader's Edition, ed. Harold W. Blodgett and Sculley Bradley (New York: New York University Press, 1965), p. 424. All subsequent references to the poem will be included in the text and will be by line number.

10 Neumann, p. 414.

11 Blodgett and Bradley, p. 626.

12 Neumann, pp. 277-278.

13 Neumann, p. 426.

14 Whitman excised eight lines from the poem at this point. Again, as in the earlier deletion, the reason is clear. The lines ["Now Lucifer Was Not Dead"] are counter to the movement of healing in the poem. See p. 627 of Blodgett and Bradley for the excised lines.

15 Neumann, pp. 15-17. 